\title{
Laboratory and Field Measurements with a Broad Band ADCP
}

\author{
Gerald F. Appell and Robert G. Williams \\ National Ocean Service \\ National Oceanic \& Atmospheric Administration \\ Silver Spring, Maryland 20910
}

\begin{abstract}
A $1200 \mathrm{kHz}$ Broad Band Acoustic Doppler Current Profiler (BBADCP) from RD Instruments was tested in 1992 to determine its applicability to National Ocean Service programs. A series of tow carriage tests was performed at the David Taylor Research Center and comparisons made with standard narrow band ADCP systems. Field tests were performed in the Patuxent River towing the BBADCP in a modified catamaran. The intent is to use the system to perform high resolution current transects from ships of opportunity in coastal waters and estuaries. These tests determined the maximum water track range and tested bottom tracking to depths of $\mathbf{4 0}$ meters. Comparisons were performed with a bottom-mounted $1200 \mathrm{kHz}$ narrow band ADCP by anchoring the catamaran $\mathbf{5 0}$ meters down river from the platform. The results showed disturbing differences that cannot be adequately explained. Data are presented showing the results of laboratory and field tests and plans are discussed for future tests.
\end{abstract}

\section{INTRODUCTION}

A program was initiated in late 1991 to evaluate a broadband acoustic Doppler current profiler (BBADCP) for use in acquiring high resolution current transect data. An RD Instruments model RD-DR 1200 with BBMOD option (broad band) was received in early January 1992. This system is a direct reading $1200 \mathrm{kHz}$ unit with flux-gate compass, pendulum tilt sensors and plastic housing. The goal of the program was to determine if the BBADCP development objectives had been met and the claimed performance achieved.

A series of tests were conducted at the David Taylor Research Center towing facility to determine BBADCP performance characteristics. This fresh water towing basin is seven meters deep, 16 meters wide, and 300 meters long. The initial tests indicated problems with the bottom tracking capability of the unit. In March 1992 RD Instruments recalled the unit and upgraded firmware to improve performance and correct the bottom tracking problem. Tow facility tests were resumed in July 1992.
In September 1992 a series of tests were conducted in the Patuxent River to evaluate the BBADCP for performing current transects. A 6-meter Hobie Cat catamaran was modified to house the BBADCP between the hulls. The catamaran was then towed by a ship over a pre-selected area of the river. A comparison was made with a $1200 \mathrm{kHz}$ $A D C P$ mounted on a bottom platform profiling to the surface. Transects were made over the bottom system and data were acquired while anchored near the ADCP.

\section{BROAD-BAND TECHNOLOGY}

RD Instruments introduced broad band signal processing technology as a commercial venture in late 1990. The development process was initiated in 1985 through a small business innovative research (SBIR) grant $[1,2]$. The objectives of the development were to obtain reduced velocity variance, shorter averaging times, and finer depth resolution than provided by the standard acoustic Doppler current profiler (ADCP). The single pulse measurement accuracy of a narrow band ADCP is dependant upon the relatively small time-bandwidth product of the received signal. In order to reduce the velocity variance a large number of pulses must be averaged, but this reduces the temporal resolution of the measurement. On shipboard or towed systems the averaging of many pulses will also reduce the spatial resolution. Broad band technology uses phase coded pulse pairs to increase the time-bandwidth product of each pulse. The velocity of the returned signal is estimated using coherent processing techniques providing improved single pulse accuracy.

The BBADCP is capable of operating in three different profiling modes. Mode 1 is for dynamic sea state conditions, mode 2 is for intermediate conditions and mode 3 is for a static sea state. It was determined that mode 2 was the best operating mode under all conditions. RD Instruments is now reconfiguring the BBADCP to operate in 5 modes. Mode 4 will be the standard operating mode and mode 5 will be a special short range, high resolution mode. Data presented herein was collected in the mode 2 setting.

The expected single ping horizontal velocity standard 
deviation with 1 meter bin widths is approximately $2.3 \mathrm{~cm} / \mathrm{s}$. Increasing the vertical resolution to 0.5 meter bins approximately doubles the expected standard deviation to 4.8 $\mathrm{cm} / \mathrm{s}$. In comparison, using RD Instruments equation (1) for narrow band $\mathrm{ADCP}$ random error determination,

$$
\alpha=\frac{1.6\left(10^{5}\right)}{F D \sqrt{N}}
$$

where

$\alpha$ is the standard deviation in meters per second,

$F$ is the frequency in hertz,

$\mathrm{D}$ is the depth cell size in meters, and

$\mathrm{N}$ is the number of pings (pulses) averaged

the expected single ping standard deviation would be greater than $13 \mathrm{~cm} / \mathrm{s}$ for the 1 meter bin widths. It would require averaging of 34 pings to achieve the predicted single ping standard deviation of the BBADCP. The ADCP would require averaging of 8 pings at 1 meter bins to match 0.5 meter bin BBADCP performance. Bottom track estimates indicate predicted standard deviations of better than $1 \mathrm{~cm} / \mathrm{s}$ at depths greater than 10 meters. Bottom tracking estimates the velocity relative to the bottom by sending out a special bottom track pulse. This pulse is different from the water track pulse and is designed for reflection from a hard target. Controlled tests were designed to determine if these performance parameters could be achieved [3].

\section{TOW CARRIAGE TESTS}

A series of tests were performed over a period of several months. The results reported are on the final modified BBADCP provided by RD Instruments in April 1992.

In order to assure optimum performance of the BBADCP in the towing basin, initial tests were conducted to determine the echo amplitude required for consistent data. Echo amplitude is a measure, in decibels, of the signal strength of the reflected transmit pulse. The useful range of the return signal is determined by the requirement that the signal strength is greater than the ambient noise level. The fresh water of the basin is filtered and does not provide sufficient acoustic scattering particles. Pulverized limestone was distributed over the length of the basin during a preliminary carriage run to boost echo amplitude. Sufficient scatterers remained in the water column for several hours before addition of limestone was required.

Test results in the water track mode gave good results in the first 4 bins with a 1 meter bin width and a 0.5 meter blanking distance. Blanking, while stated in terms of distance, is a time delay during which received echoes are not processed. Contamination of the measurements from the first bin may occur if the transducer is still "ringing" during processing of the first received echoes. Data were recorded over a speed range of $5 \mathrm{~cm} / \mathrm{s}$ to $400 \mathrm{~cm} / \mathrm{s}$. Single ping ensembles were recorded approximately every second. The results were in close agreement with the predicted theoretical standard deviation. Data displayed in Figure 1 show a range of standard deviations of from 2 to $3 \mathrm{~cm} / \mathrm{s}$. The error in the mean is largest at $0 \mathrm{~cm} / \mathrm{s}$ speed, showing a positive offset of $3 \mathrm{~cm} / \mathrm{s}$. The increasing speed data show a negative slope to the error with a $-2 \mathrm{~cm} / \mathrm{s}$ error at a speed of $400 \mathrm{~cm} / \mathrm{s}$. Similar results were obtained during tow carriage tests of the narrow band ADCP with multiple ping ensemble averaging [3]. That data showed an error range of from $0.5 \mathrm{~cm} / \mathrm{s}$ at low speeds to $-3.8 \mathrm{~cm} / \mathrm{s}$ at a speed of $300 \mathrm{~cm} / \mathrm{s}$.

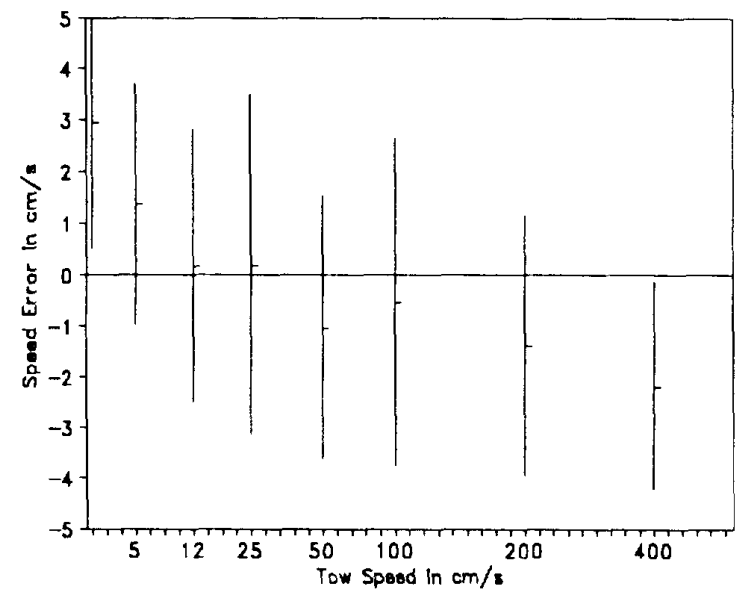

Figure 1. Water track calibration data showing the mean error and standard deviation of 10 single ping ensembles from the first 4 bins.

Tests were conducted with bottom track on and one bottom track ping sent for every water track ping. Data were recorded over the same speed as the water track. Figure 2 shows considerable improvement in the mean error over water track except at $400 \mathrm{~cm} / \mathrm{s}$. The standard deviation is also smaller than water track, generally within $1 \mathrm{~cm} / \mathrm{s}$. The single ping bottom track results also compares favorably with the narrow band multiple ping data [3]. Those results showed maximum bottom track errors of $-1.5 \mathrm{~cm} / \mathrm{s}$ at a speed of $200 \mathrm{~cm} / \mathrm{s}$.

The tow tank calibration of the BBADCP confirmed the predicted performance. Similarities with the narrow band ADCP are that they both show significant zero flow offsets in water tracking and they both exhibit a negative slope in the mean errors at increasing speeds. In general, the results show that single ping BBADCP ensembles can be used to acquire data that is comparable to multiple ping ADCP data. 


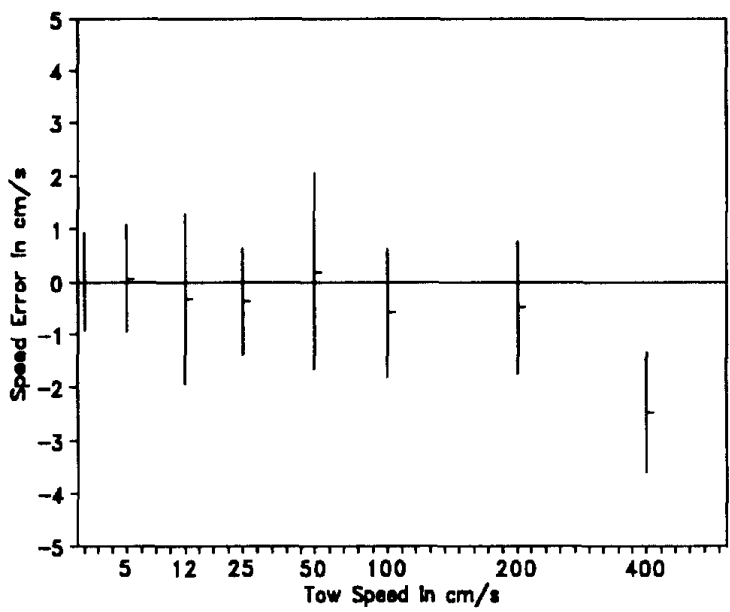

Figure 2. Bottom track calibration data showing the mean error and standard deviation of 10 single ping ensembles.

\section{PATUXENT RIVER TESTS}

The Patuxent River area near Solomons, Maryland, was selected as a field test site for several reasons. Geographically, the site is near the mouth of the river as it empties into the Chesapeake Bay. Logistically, it provides marinas and the Navy piers of the Naval Recreation Center, to support operations. This area of the river provides several interesting features to facilitate evaluation of the system under a wide range of environmental conditions. There is a constriction in the river caused by a spit of land called Pt. Patience which results in a shallow area of one to two meter depth rapidly progressing to a 40 meter deep hole over a horizontal distance of $\mathbf{3 0 0}$ meters. Further downstream the river widens to provide a transect width of two kilometers with a flat bottom of about 18 meters depth. This area was suitable for placement of a $1200 \mathrm{kHz}$ narrow band ADCP on a bottom platform in the middle of the river. The ADCP was used to provide "ground truth" from a stationary platform.

Initial tests were conducted in the deep area near Pt. Patience. The catamaran, a 6-meter Hobie Cat, was towed with the BBADCP mounted between the hulls and the transducer submerged to a depth of approximately $0.5 \mathrm{~m}$. Absolute position was determined by LORAN-C. The BBADCP was programmed for 40 bins, one meter bin length, two meter blanking distance, and one water track and one bottom track ping per ensemble. The catamaran was towed across the river at a speed of $2.5 \mathrm{~m} / \mathrm{s}$. The results were encouraging showing good water track data to a depth of 35 meters and bottom tracking to the maximum depth of 40 meters. Echo amplitude was approximately $65 \mathrm{~dB}$ near the surface decreasing to about $50 \mathrm{~dB}$ at 18 meters and remaining relatively constant down to the bottom.

The most interesting tests were conducted near the bottommounted ADCP. The towing vessel, NOAA's $R / V$ LAIDLY deployed a 2-point mooring approximately 20 meters downstream from the bottom-mounted ADCP and tethered the catamaran on the end of a 10 meter line. On this particular day in September, 1992, strong north winds set up a one meter wind-wave chop on the river. This relatively rough surface caused the catamaran to pitch, roll, and yaw about its tether. The BBADCP was set up for one meter bin width, 0.5 meter blanking distance, and one water track and one bottom track ping per ensemble. One ensemble was recorded approximately every 1.3 seconds. The bottom $A D C P$ was programmed for a one meter bin width, 0.5 meter blanking distance, and 285 pings per two minute ensemble. These settings theoretically provide a resolution of at least one $\mathrm{cm} / \mathrm{s}$ per ensemble. One hour of intercomparison data were recorded.

Significant differences were found in the data obtained by the two systems. Tidal flows in that area of the river are predominantly East-West. The BBADCP velocity profiles show a strong shear with a reversing flow near the bottom. At near-bottom depths of 10 to 12 meters the data indicate flows of 15 to $20 \mathrm{~cm} / \mathrm{s}$ in a westerly direction. The velocity profile in the first eight meters depth shows slack water to three $\mathrm{cm} / \mathrm{s}$ in an easterly direction. The bottom-mounted ADCP showed good agreement with the BBADCP near the bottom in the first three profiling bins. However, the ADCP data indicate relatively uniform flow 10 to $15 \mathrm{~cm} / \mathrm{s}$ westerly from bottom to top. The divergence between the two systems occurred at a depth of 10 meters and increased toward the surface (Figure 3).

Closer examination of the data showed that the compass in the BBADCP was oscillating in response to the rough sea, with apparently inadequate damping. In processing the data with bottom track correction, the interpretation of the direction of the current flow is apparently erroneous due to a mismatch in time constants. The compass is not designed to operate under the severe dynamic conditions that were encountered. Preliminary evaluation indicated a similar situation with regard to the pitch and roll sensors, i.e., poor dynamic response characteristics for rough sea. The catamaran platform did not have adequate stability under these conditions to obtain good measurements with the presently configured BBADCP. Additional uncertainty in 


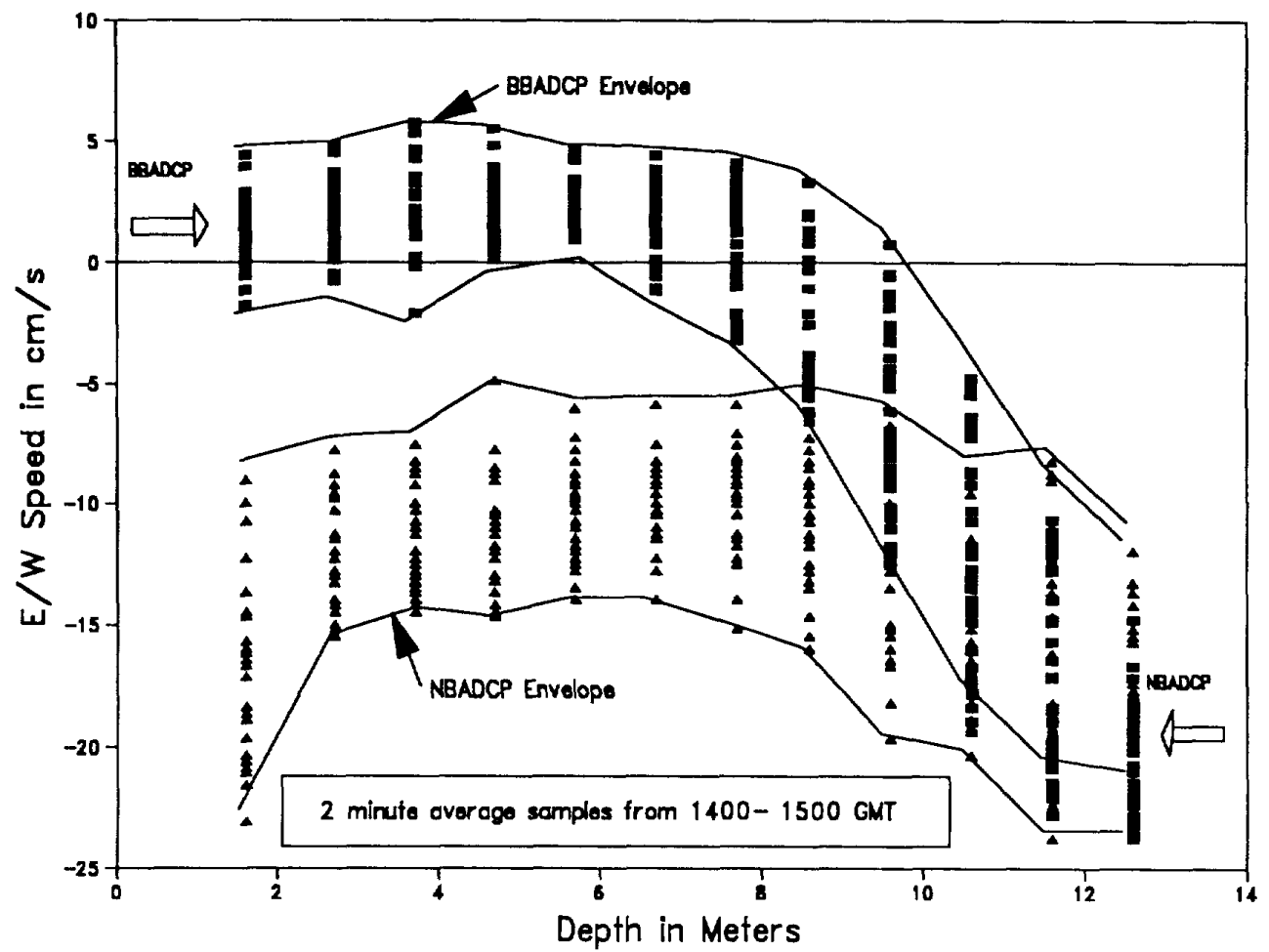

Figure 3. Intercomparison of the downward looking BBADCP on an anchored catamaran with an upward looking ADCP.

the intercomparison tests was caused by the physical separation of the instruments in a stratified, turbulent environment. There are too many unknown factors in the present datasets to apportion the variance to particular physical causes.

\section{FUTURE PLANS}

We plan to conduct additional tests to verify the suspected dynamics effect on the performance of the BBADCP. Two bottom platforms will be deployed in close proximity, one with an $\mathrm{ADCP}$ and the other with a BBADCP to confirm that without dynamic forcing of the compass, comparable data can be obtained. A second series of tests will be conducted with the catamaran employing the ADCP and BBADCP mounted in parallel in the downward-facing configuration. Tows and anchored tests will be conducted over the bottom platform under initially quiescent conditions in an area of smooth bottom and uniform, homogeneous flow. As data comparability is achieved, tests will be conducted under increasingly dynamic conditions.
Operations on the continental shelf, where one meter or higher seas are typical, will require a new, more stable platform, and more heavily damped motion sensors in the BBADCP with matched time constants.

\section{REFERENCES}

[1] B. Brumley, R. Cabrera, K. Deines, and E. Terray, "Performance of a Broad-Band Acoustic Doppler Current Profiler," IEEE Joumal of Oceanic Engineering, Vol. 16, No. 4, October 1991.

[2] H. Schoeberlein, M. Baker, and J. Fetter, "Comparison of Broad-Band Acoustic Doppler Current Profiler Performance with Theoretical Predictions," Proceedings of OCEANS'91, Vol. 2, pp. 992-996, October 1991.

[3] G. Appell, J, Gast, R. Williams, and P., Bass, "Calibration of Acoustic Doppler Current Profilers," Proceedings of Oceans'88, Baltimore, Maryland, October 31-November 2, 1988.

[4] G. Appell, H., Shih, W., Wilmot, "Development of a Towed System for Remote Acoustic Doppler Current Measurement," Proceedings of the Energy-Sources Techmology Conference and Exhibition, Houston, Texas, January 22-25, 1989. 